\title{
Responses of Metabolites in Soybean Shoot Apices to Changing Atmospheric Carbon Dioxide Concentrations
}

\author{
Richard Sicher \\ Crop Systems \& Global Change Laboratory, Agricultural Research Service-USDA, Room 342, Building 001, BARC-west, 10300 \\ Baltimore Avenue, Beltsville, MD 20705, USA \\ Correspondence should be addressed to Richard Sicher, richard.sicher@ars.usda.gov \\ Received 12 June 2012; Accepted 11 July 2012 \\ Academic Editor: Bernd Lennartz \\ Copyright (c) 2012 Richard Sicher. This is an open access article distributed under the Creative Commons Attribution License, \\ which permits unrestricted use, distribution, and reproduction in any medium, provided the original work is properly cited. \\ Soybean seedlings were grown in controlled environment chambers with $\mathrm{CO}_{2}$ partial pressures of 38 (ambient) and 72 (elevated) \\ $\mathrm{Pa}$. Five or six shoot apices were harvested from individual 21- to 24-day-old plants. Metabolites were analyzed by gas \\ chromatography and, out of 21 compounds, only sucrose and fructose increased in response to $\mathrm{CO}_{2}$ enrichment. One unidentified \\ metabolite, Unk-21.03 decreased up to $80 \%$ in soybean apices in response to elevated $\mathrm{CO}_{2}$. Levels of Unk-21.03 decreased \\ progressively when atmospheric $\mathrm{CO}_{2}$ partial pressures were increased from 26 to $100 \mathrm{~Pa}$. Reciprocal transfer experiments showed \\ that Unk-21.03, and sucrose in soybean apices were altered slowly over several days to changes in atmospheric $\mathrm{CO}_{2}$ partial \\ pressures. The mass spectrum of Unk-21.03 indicated that this compound likely contained both an amino and carboxyl group and \\ was structurally related to serine and aspartate. Our findings suggested that $\mathrm{CO}_{2}$ enrichment altered a small number of specific \\ metabolites in soybean apices. This could be an important step in understanding how plant growth and development are affected \\ by carbon dioxide enrichment.
}

\section{Introduction}

Atmospheric $\mathrm{CO}_{2}$ partial pressures are increasing due to human activities that include industrialization, fossil fuel combustion, and deforestation [1]. Since $\mathrm{CO}_{2}$ is an important substrate for photosynthesis, elevated atmospheric $\mathrm{CO}_{2}$ has the potential to alter the productivity of terrestrial plants and that of natural or managed ecosystems [2]. Single leaf gas exchange rates of higher plants were affected by $\mathrm{CO}_{2}$ enrichment, and this often resulted in larger plants with increased reproductive capacity [3-5]. Due to accelerated rates of net $\mathrm{CO}_{2}$ assimilation, concentrations of various leaf components including starch, soluble carbohydrates, amines, organic acids, pigments, and important photosynthetic proteins were affected by plant growth in $\mathrm{CO}_{2}$-enriched atmospheres [6-8]. Increased biomass accumulation in response to $\mathrm{CO}_{2}$ enrichment impacted the demand for soil nutrients, and in some cases this resulted in nutritionally limited growth conditions [9]. Nutrient limitations under $\mathrm{CO}_{2}$ enrichment also decreased leaf photosynthetic capacity and further altered leaf constituents [8].
In comparison to source leaves, much less attention has been given to the effects of elevated $\mathrm{CO}_{2}$ on the growth and development of sinks. Sink organs are dependent upon source leaves for assimilates to provide the carbon, nitrogen, and energy needed for growth and development. In general, metabolite levels in sink tissues were altered in concert with changes in source leaves on the same plant. For example, Geiger et al. [8] reported that starch, sucrose, and reducing sugars were increased by $\mathrm{CO}_{2}$ enrichment in unopened sink leaves of tobacco. Hexoses and sucrose also were increased by $\mathrm{CO}_{2}$ enrichment in studies of roots from seedlings of tobacco and barley $[8,10]$. Components of reproductive tissues and seeds also were affected by $\mathrm{CO}_{2}$ enrichment. For example, doubling ambient $\mathrm{CO}_{2}$ levels throughout plant development increased soybean seed oil content by 1 or $2 \%$ with a commensurate decrease in seed protein content $[11,12]$. Ziska et al. [13] also reported that omega-3 fatty acids were increased in mungbean seeds by doubling the ambient $\mathrm{CO}_{2}$ partial pressure, and Wang et al. [14] observed that antioxidant levels in strawberry fruit were increased by $\mathrm{CO}_{2}$ enrichment. 
The present study examined metabolite changes in soybean apices in response to varying $\mathrm{CO}_{2}$ partial pressures during plant growth. Apical tissue contains the meristem, leaf primordia, and other rapidly differentiating tissues, that are critical determinants of shoot growth and development. Kinsman et al. [15] previously showed that $\mathrm{CO}_{2}$ enrichment shortened cycling times of rapidly dividing cells in the shoot and root meristems of Dactylis glomerata. Since specific metabolites are capable of modifying gene expression, we hypothesized that changes of metabolites in shoot apices in response to $\mathrm{CO}_{2}$ enrichment could be important in regulating shoot growth. The current study describes changes of three metabolites that varied in soybean shoot apices in response to $\mathrm{CO}_{2}$ enrichment.

\section{Materials and Methods}

2.1. Plant Materials. Soybean [Glycine max (L.) Merr. cv. Williams] plants were grown in matching pairs of controlled environment chambers (model M-2, Environmental Growth Chamber Corp., Chagrin Falls, OH, USA) as described previously [16]. Individual seeds were planted in $1.8 \mathrm{dm}^{3}$ plastic pots filled with vermiculite and the pots were watered once daily with a complete mineral nutrient solution containing $12 \mathrm{mM}$ nitrate and $2.5 \mathrm{mM}$ ammonium. After $17 \mathrm{ds}$ of growth, plants were watered twice daily to insure adequate nutrient supply. The air temperature was $27 \pm 1^{\circ} \mathrm{C}$, the PPFD was $850 \pm 40 \mu \mathrm{mol} \mathrm{m}^{-2} \mathrm{~s}^{-1}$, and the photoperiod used a $14 \mathrm{~h}$ day $/ 10 \mathrm{~h}$ night cycle. Ambient and elevated chamber air $\mathrm{CO}_{2}$ partial pressures were normally $38 \pm 10$ and $72 \pm 10 \mathrm{~Pa}$, respectively and were varied as indicated in the text. Reciprocal transfer experiments were performed 21 DAS by switching half of the ambient and elevated $\mathrm{CO}_{2}$ grown plants to the opposite $\mathrm{CO}_{2}$ treatment. Apices from switched plants were harvested daily for the next $3 \mathrm{ds}$. Apical tissue was normally harvested from the main shoot and from 4 or 5 lateral branches. A total of 4 or 5 apices from an individual plant were combined and transferred to $1.5 \mathrm{~mL}$ Eppendorf tubes. Collecting apices from an individual plant normally took about $1 \mathrm{~min}$. Tubes containing the harvested apices were quickly sealed and immersed in liquid $\mathrm{N}_{2}$ to quench metabolism. Apical samples could be stored at $-80^{\circ} \mathrm{C}$ for up to 1 month prior to analysis without altering results. Preliminary experiments showed that metabolite concentrations in apical tissue did not differ between the main shoot and lateral branches. At each time point, four individual plants were harvested from either $\mathrm{CO}_{2}$ treatment. Metabolite measurements from four individual plants were combined, and experiments were replicated at least once. Results are presented as means from the combined experiments and significant differences were determined using Student's $t$ test.

2.2. Component Analysis. Metabolite concentrations were determined by gas chromatography according to Roessner et al. [17]. Isolated apices from a single plant ( $25 \mathrm{mg} \mathrm{FW})$ were extracted at $4^{\circ} \mathrm{C}$ with $1.4 \mathrm{~mL}$ methanol using a ground glass tissue homogenizer. Prior to extraction, $0.1 \mathrm{mg}$ of adonitol (ribitol) was added to each sample, and this served as an internal standard. The homogenates were incubated in a $\mathrm{H}_{2} \mathrm{O}$ bath at $70^{\circ} \mathrm{C}$ for $15 \mathrm{~min}$ and allowed to cool before dilution with an equal volume of deionized $\mathrm{H}_{2} \mathrm{O}$. The diluted extracts were centrifuged at $6000 \mathrm{~g}$, and $20 \mu \mathrm{L}$ of supernatant was transferred to a $1 \mathrm{~mL}$ ReactiVial and dried overnight in a desiccator under vacuum. Dried samples and appropriate standards were dissolved in $100 \mu \mathrm{L}$ of pyridine containing $2 \mathrm{mg}$ of methoxyamine and were then incubated in a $\mathrm{H}_{2} \mathrm{O}$ bath at $30^{\circ} \mathrm{C}$ for $90 \mathrm{~min}$ with continuous shaking. Subsequently, $50 \mathrm{~mL}$ of MSTFA [N-methyl-N-(trimethylsilyl)fluoroacetamide] was added to each vial, which was then incubated as above for $30 \mathrm{~min}$ at $37^{\circ} \mathrm{C}$. Derivatized samples and standards were separated by gas chromatography (model 6890A, Hewlett Packard), and metabolites were detected with a mass selective detector (model 7125, Agilent Technologies, Wilmington, DE, USA) coupled to Agilent MSD Chemstation Software. Separations were performed with a $30 \mathrm{~m} \times 0.25 \mathrm{~mm}$ Supelco SPB-50 column (Sigma-Aldrich, St. Louis, MO, USA) using highpurity helium as a carrier gas at $1.2 \mathrm{~mL} \mathrm{~min}^{-1}$. The oven temperature was increased at $5^{\circ} \mathrm{C} \mathrm{min}^{-1}$ from 70 to $310^{\circ} \mathrm{C}$ and a solvent delay of $8.5 \mathrm{~min}$ was used. The detector was operated in full-scan mode at 50 scans $\mathrm{min}^{-1}$ with a range of $0-550 \mathrm{~m} / \mathrm{z}$. Total ion chromatograms were quantified using peak identification and calibration parameters within the Chemstation program. Standard curves were prepared with a mixture of known concentrations of specific compounds, and sample quantitation was performed using slopes derived by linear regression.

\section{Results}

3.1. Isolated Apical Tissue. Figure 1 shows the magnified images of the soybean shoot tip and of an excised shoot apex. The shoot apex was readily separated from the uppermost node on the stem and, upon visual inspection, this tissue was composed mostly of nascent leaves that were covered by numerous trichomes. Individual soybean plants possessed 6 or 7 lateral branches when harvested between 21 and 24 DAS. Total mass of the isolated shoot apex averaged about $5 \mathrm{mg}$ FW each, whereas apices from lateral branches were 3 to $4 \mathrm{mg}$ FW each.

\subsection{Effects of $\mathrm{CO}_{2}$ Enrichment on Metabolite Levels in Soybean Apices. Concentrations of 21 individual compounds in shoot apices are shown in Figure 2. Sucrose and fructose levels in isolated apical tissue increased by $23 \%$ and $41 \%$, respectively, in response to $\mathrm{CO}_{2}$ enrichment $(P \leq 0.05)$. In addition to the known compounds discussed above, an unknown compound with a retention time of $21.03 \mathrm{~min}$ (Unk-21.03) decreased 50 to $80 \%$ when the ambient $\mathrm{CO}_{2}$ partial pressure was doubled (compare Figures 3(a) and 3(b)). Levels of Unk- 21.03 in soybean apices decreased in proportion to the $\mathrm{CO}_{2}$ partial pressure when chamber air $\mathrm{CO}_{2}$ levels were increased from 26 to $100 \mathrm{~Pa}$ (Figure 4(a)). The mass spectrum of this unidentified compound contained major mass fragments at}




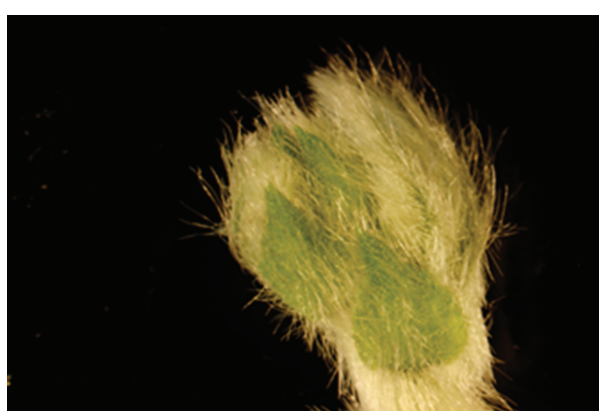

(a)

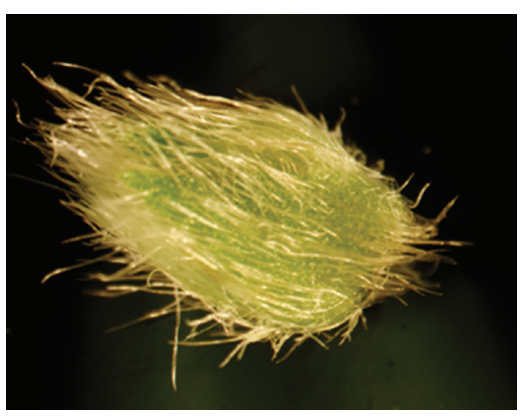

(b)

Figure 1: Manual isolation of soybean apices from the shoot tip. (a) Image of soybean shoot tip (10x); (b) image of isolated apical tissue from the main shoot (40x).

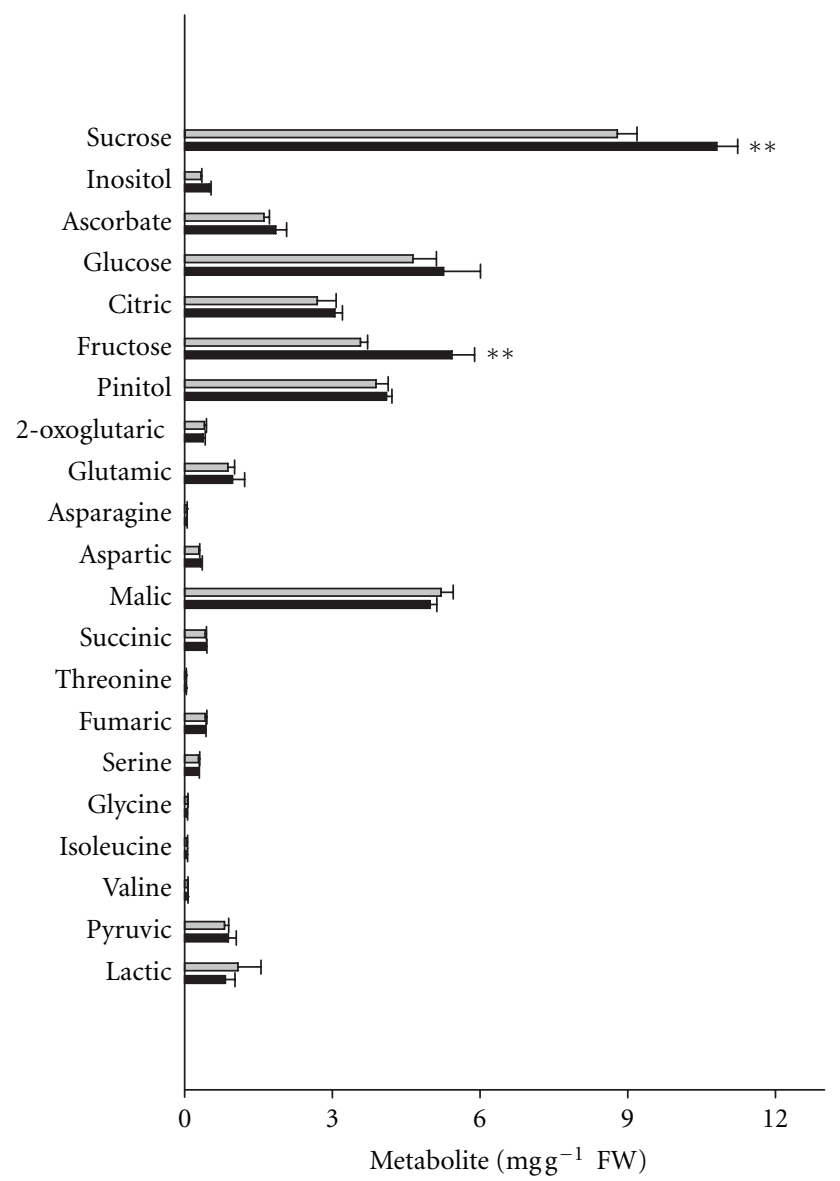

FIGURE 2: Responses of metabolites in soybean apices to $\mathrm{CO}_{2}$ enrichment. Measurements were performed on apices harvested from plants grown with 38 (no fill) or $72 \mathrm{~Pa} \mathrm{CO}_{2}$ (black fill). (**) denotes significant differences at $P \leq 0.01$.

$m / z 147,205,234$, and 306 and the signature mass had an $\mathrm{m} / \mathrm{z}$ of 423 (Figure $4(\mathrm{~b})$ ).

3.3. Effects of Switching $\mathrm{CO}_{2}$ Treatments on Metabolite Levels in Soybean Apices. The effects of reversing the ambient and elevated $\mathrm{CO}_{2}$ treatments on sucrose and on Unk-21.03 levels in soybean apices are shown in Figure 5. Soybean apices were initially sampled 21 DAS and harvests continued daily for the next $3 \mathrm{ds}$. When averaged over all measurement dates, sucrose levels in soybean apices were enhanced $28 \%$ in the elevated compared to the ambient $\mathrm{CO}_{2}$ treatment. Differences in sucrose due to $\mathrm{CO}_{2}$ enrichment disappeared 3 ds after plants were switched from the elevated to the ambient $\mathrm{CO}_{2}$ treatment. Conversely, transferring plants from the ambient to the elevated $\mathrm{CO}_{2}$ treatment did not affect sucrose concentrations in soybean apices over the duration of the 3-day experiment. As shown in Figure 3, the peak area attributable to Unk-21.03 was $80 \%$ less in soybean apices from the elevated compared to the ambient $\mathrm{CO}_{2}$ treatment (Figure 5(b)). Transferring plants grown at $72 \mathrm{~Pa} \mathrm{CO}_{2}$ to ambient $\mathrm{CO}_{2}$ increased levels of Unk-21.03 in soybean apices by $19 \%$ in 3 ds and the reciprocal transfer decreased levels of Unk- 21.03 by $50 \%$ over the same time period. Similar effects of $\mathrm{CO}_{2}$ enrichment on Unk-21.03 concentrations were observed in soybean root tissue, but levels of Unk-21.03 were variable in leaf tissue and were not affected by the elevated $\mathrm{CO}_{2}$ treatment (data not shown).

\section{Discussion}

Current atmospheric $\mathrm{CO}_{2}$ levels do not saturate rates of photosynthesis by terrestrial plants having the $\mathrm{C}_{3}$ photosynthetic pathway $[2,18]$. Therefore, elevated $\mathrm{CO}_{2}$ usually increases rates of photosynthesis and inhibits photorespiration by source leaves. These effects on gas exchange usually result in increased carbohydrate synthesis and enhanced $\mathrm{C} / \mathrm{N}$ ratios of many higher plant species [8]. Since sucrose and other soluble sugars are exported from source leaves, $\mathrm{CO}_{2}$ enrichment often elevates soluble carbohydrates and starch in sink tissues. Although very little is known about the biochemical components of soybean apices, the finding that this tissue contained increased concentrations of sucrose or fructose was not altogether surprising. Glucose and fructose are equimolar constituents of sucrose, and these two hexoses occur in plant tissues when sucrose is hydrolyzed enzymically [19]. The finding that glucose was unaffected by $\mathrm{CO}_{2}$ enrichment suggested that it was preferentially metabolized by soybean apices in comparison to fructose. No other 


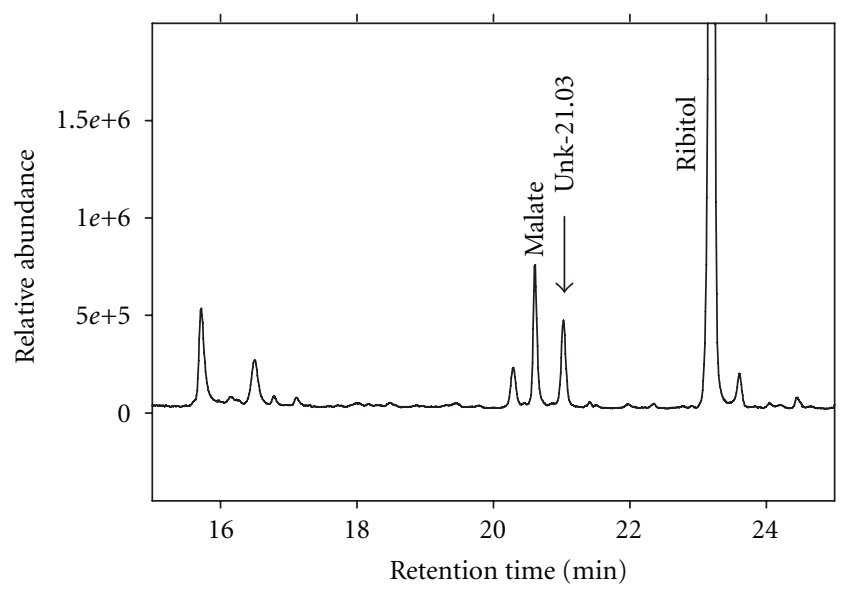

(a) $36 \mathrm{~Pa} \mathrm{CO}_{2}$

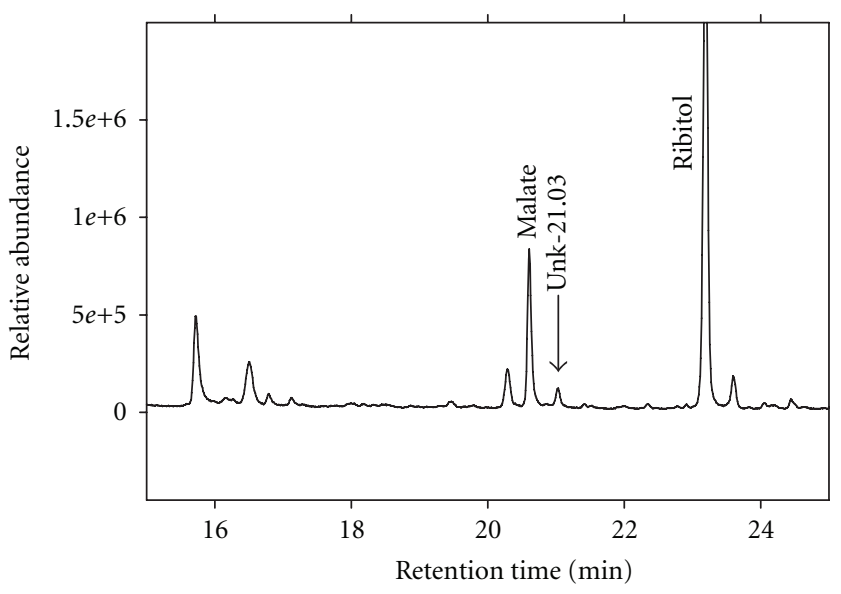

(b) $72 \mathrm{~Pa} \mathrm{CO}_{2}$

FIGURE 3: Total ion chromatogram showing changes of an unidentified compound (Unk-21.03) that decreased in soybean apices in response to $\mathrm{CO}_{2}$ enrichment. Chromatograms were prepared with similar amounts of extracts of soybean apices from the ambient (a) and elevated (b) $\mathrm{CO}_{2}$ treatments. The unidentified compound eluted from the column at 21.03 minutes and is marked with a descending arrow. Values are means $\pm \mathrm{SE}(n=8)$.

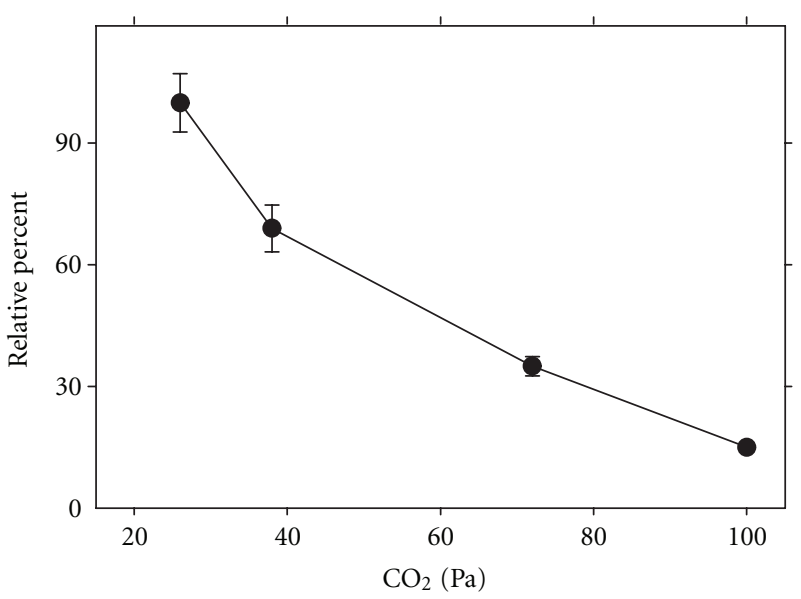

(a)

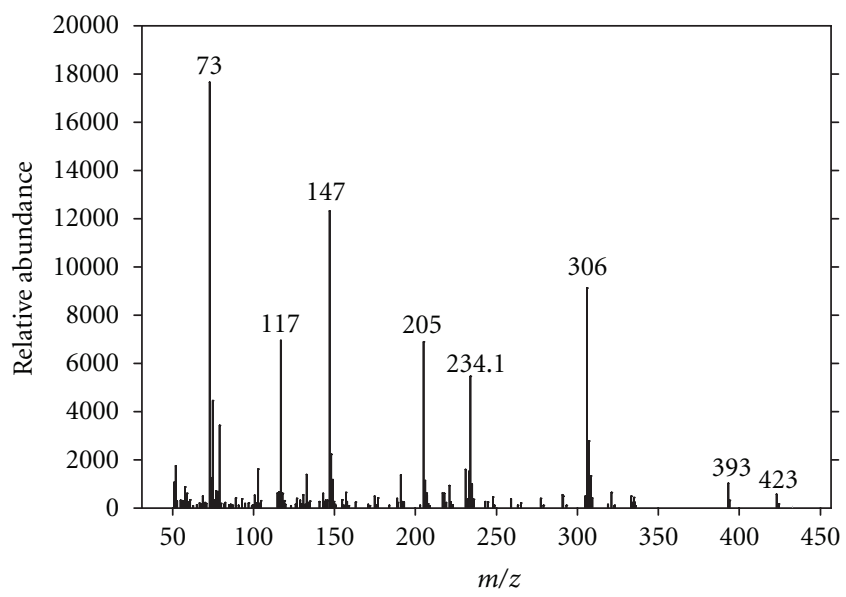

(b)

FIGURE 4: Inverse relationship between Unk-21.03 and increasing partial pressures of atmospheric $\mathrm{CO}_{2}$. (a) Plants were grown for 21 ds at four different partial pressures of $\mathrm{CO}_{2}$ prior to analyzing for Unk-21.03. Values on the $y$-axis are integrated peak areas normalized by the mass of apical tissue in each sample. (b) The mass spectrum of Unk-21.03.

compound that we measured in soybean apices increased in response to $\mathrm{CO}_{2}$ enrichment.

Growth rates of soybean are usually accelerated by $\mathrm{CO}_{2}$ enrichment, and this creates an increased demand for soil nutrients $[4,8,10]$. Nutrient limiting conditions can occur in experiments employing $\mathrm{CO}_{2}$ enrichment, particularly, if soil fertility is not monitored carefully $[8,9]$. Nitrogen-limiting conditions inhibit the synthesis of essential aminoacids and proteins and decreases of inorganic $\mathrm{N}$ in leaves and other plant parts. Results of Figure 1 showed that important soluble aminoacids in soybean apices were unaffected by $\mathrm{CO}_{2}$ enrichment. This finding suggested that nutrient limiting conditions did not influence the results of this study. In a prior report [16], asparagine was the most abundant amino acid in soybean trifoliolates. Therefore, it was interesting that asparagine was a minor constituent of soybean apices.

Only one metabolite in soybean apices, Unk-21.03, decreased in response to $\mathrm{CO}_{2}$ enrichment, and Unk-21.03 was progressively decreased by $\mathrm{CO}_{2}$ partial pressures that ranged from 26 to $100 \mathrm{~Pa}$. Overall, Unk-21.03 the most $\mathrm{CO}_{2}$ responsive metabolite observed in this investigation. Reciprocal transfer experiments showed that changes of Unk-21.03 in soybean apices occurred over a period of several days in response to an abrupt change in $\mathrm{CO}_{2}$ partial pressure. A more rapid response to a change in $\mathrm{CO}_{2}$ partial pressure would have occurred, if changes of Unk-21.03 in the shoot apex were the direct result of an internal $\mathrm{CO}_{2}$ fixation reaction or were due to $\mathrm{CO}_{2}$ effects on photorespiration. If 


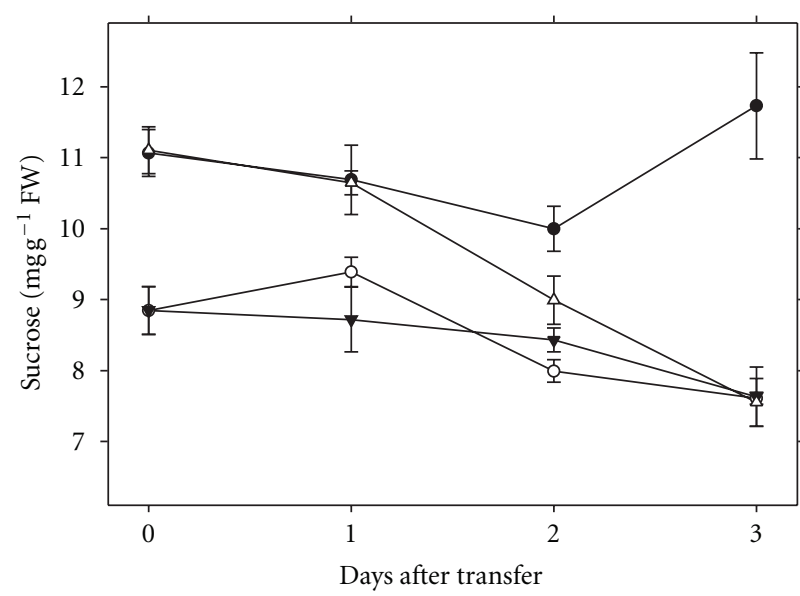

(a)

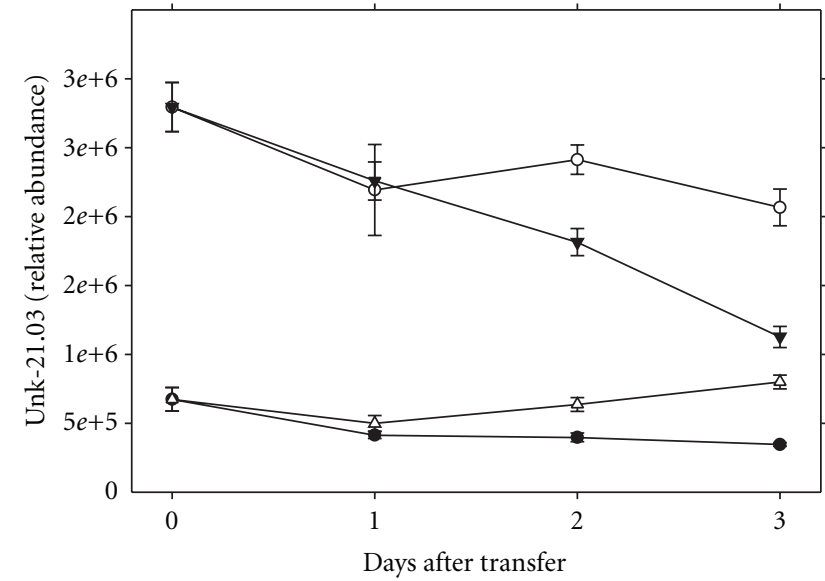

(b)

FIGURE 5: Effects of reversing the ambient and elevated $\mathrm{CO}_{2}$ treatments on metabolite levels in soybean apices. Sucrose (a) and Unk-21.03 (b) were measured in soybean apices using plants that were grown for a total of $24 \mathrm{~d}$ in the ambient $(\circ)$ and elevated $(\bullet) \mathrm{CO}_{2}$ treatments. Reciprocal transfers were performed 21 DAS by switching one-half the plants from ambient to elevated $\mathrm{CO}_{2}(\Delta)$ and vice versa $(\boldsymbol{\Delta})$. Values are means $\pm \mathrm{SE}(n=8)$.

the synthesis of Unk-21.03 was dependent on the activity of phospho(enol)pyruvate carboxylase much more rapid changes in tissue concentrations would be expected in response to fluctuating atmospheric $\mathrm{CO}_{2}$ concentrations. Responses of sucrose levels in soybean apices were similarly delayed by a reciprocal shift in $\mathrm{CO}_{2}$ levels. These findings suggested that Unk-21.03 may have been synthesized elsewhere on the plant and transported to the shoot apex.

The identification of Unk-21.03 is incomplete. However, the mass spectrum indicates that Unk-21.03 is probably an amine. A prominent ion with $\mathrm{m} / \mathrm{z}=306$ is also present in aspartic acid and serine. These two aminoacids share the root structure $\mathrm{RCH}_{2} \mathrm{CH}\left(\mathrm{NH}_{2}\right) \mathrm{COOH}$. The $\mathrm{R}$ group in the serine molecule is a hydroxyl, and this is replaced in aspartic acid by a carboxyl moiety. To test this idea further, a concentrated extract of Unk-21.03 from soybean roots was separated by ascending thin layer chromatography, and the band associated with Unk-21.03 was detected with a spray containing bromphenol blue. A blue band was observed confirming that Unk-21.03 contained a carboxyl group. Since the ion attributed to $\mathrm{m} / \mathrm{z}=306$ is not commonly found in small molecules from plant extracts, it is probable that Unk-21.03 contains the root structure described above. If this assumption is correct, Unk-21.03 was likely derived from serine or aspartate. It is interesting that Unk-21.03 decreased in soybean apices in response to $\mathrm{CO}_{2}$ enrichment, whereas the possible precursors of Unk-21.03, serine and aspartate, were unchanged (see Figure 1). A possible explanation for these observations was that these compounds were synthesized elsewhere on the plant and imported into the apical tissue.

There is abundant evidence from higher plant species that multiple compounds involved in primary metabolism were altered in leaves and other plant tissues by $\mathrm{CO}_{2}$ enrichment $[7,8,10]$. The finding that Unk-21.03 levels in soybean apices were decreased up to $80 \%$ by $\mathrm{CO}_{2}$ enrichment is potentially significant. Identifying Unk-21.03 and determining how $\mathrm{CO}_{2}$ enrichment affected levels of this compound in sink tissues could be an important step in understanding plant growth responses to $\mathrm{CO}_{2}$ enrichment.

\section{Abbreviations}

DAS: Days after sowing

PPFD: Photosynthetic photon flux density.

\section{Acknowledgments}

The author thanks Steve Emche and Robert Erdman for assistance with gas chromatography and metabolite analysis. J. Y. Barnaby provided helpful comments on the paper.

\section{References}

[1] R. A. Houghton, "Revised estimates of the annual net flux of carbon to the atmosphere from changes in land use and land management 1850-2000," Tellus B, vol. 55, no. 2, pp. 378-390, 2003.

[2] G. Bowes, "Facing the inevitable: plants and increasing atmospheric $\mathrm{CO}_{2}$," Annual Review of Plant Physiology and Plant Molecular Biology, vol. 44, no. 1, pp. 309-332, 1993.

[3] B. A. Kimball, J. R. Mauney, F. S. Nakayama, and S. B. Idso, "Effects of increasing atmospheric $\mathrm{CO}_{2}$ on vegetation," Vegetatio, vol. 104-105, no. 1, pp. 65-75, 1993.

[4] L. H. Ziska, J. A. Bunce, and F. Caulfield, "Intraspecific variation in seed yield of soybean (Glycine max) in response to increased atmospheric carbon dioxide," Australian Journal of Plant Physiology, vol. 25, no. 7, pp. 801-807, 1998.

[5] E. A. Ainsworth, P. A. Davey, C. J. Bernacchi et al., "A metaanalysis of elevated $\left[\mathrm{CO}_{2}\right]$ effects on soybean (Glycine max) physiology, growth and yield," Global Change Biology, vol. 8, no. 8, pp. 695-709, 2002. 
[6] G. Y. Nie, S. P. Long, R. L. Garcia et al., "Effects of free-air $\mathrm{CO}_{2}$ enrichment on the development of the photosynthetic apparatus in wheat, as indicated by changes in leaf proteins," Plant, Cell \& Environment, vol. 18, no. 8, pp. 855-864, 1995.

[7] R. C. Sicher and J. A. Bunce, "Relationship of photosynthetic acclimation to changes of Rubisco activity in field-grown winter wheat and barley during growth in elevated carbon dioxide," Photosynthesis Research, vol. 52, no. 1, pp. 27-38, 1997.

[8] M. Geiger, V. Haake, F. Ludewig, U. Sonnewald, and M. Stitt, "The nitrate and ammonium nitrate supply have a major influence on the response of photosynthesis, carbon metabolism, nitrogen metabolism and growth to elevated carbon dioxide in tobacco," Plant, Cell \& Environment, vol. 22, no. 10, pp. 1177-1199, 1999.

[9] W. J. Arp, "Effects of source-sink relations on photosynthetic acclimation to elevated $\mathrm{CO}_{2}$," Plant, Cell \& Environment, vol. 14 , no. 8, pp. 869-875, 1991.

[10] R. C. Sicher, "Interactive effects of inorganic phosphate nutrition and carbon dioxide enrichment on assimilate partitioning in barley roots," Physiologia Plantarum, vol. 123, no. 2, pp. 219-226, 2005.

[11] J. M. G. Thomas, K. J. Boote, L. H. Allen Jr., M. GalloMeagher, and J. M. Davis, "Elevated temperature and carbon dioxide effects on soybean seed composition and transcript abundance," Crop Science, vol. 43, no. 4, pp. 1548-1557, 2003.

[12] R. Sicher, J. Bunce, and B. Matthews, "Differing responses to carbon dioxide enrichment by a dwarf and a normal-sized soybean cultivar may depend on sink capacity," Canadian Journal of Plant Science, vol. 90, no. 3, pp. 257-264, 2010.

[13] L. H. Ziska, R. Palowsky, and D. R. Reed, "A quantitative and qualitative assessment of mung bean (Vigna mungo (L.) Wilczek) seed in response to elevated atmospheric carbon dioxide: potential changes in fatty acid composition," Journal of the Science of Food and Agriculture, vol. 87, no. 5, pp. 920923, 2007.

[14] S. Y. Wang, J. A. Bunce, and J. L. Maas, "Elevated carbon dioxide increases contents of antioxidant compounds in field-grown strawberries," Journal of Agricultural and Food Chemistry, vol. 51, no. 15, pp. 4315-4320, 2003.

[15] E. A. Kinsman, C. Lewis, M. S. Davies et al., "Elevated $\mathrm{Co}_{2}$ stimulates cells to divide in grass meristems: a differential effect in two natural populations of Dactylis glomerata," Plant, Cell \& Environment, vol. 20, no. 10, pp. 1309-1316, 1997.

[16] R. C. Sicher, "Daily changes of amino acids in soybean leaflets are modified by $\mathrm{CO}_{2}$ enrichment," International Journal of Plant Biology, vol. 1, no. 18, pp. 89-893, 2010.

[17] U. Roessner, C. Wagner, J. Kopka, R. N. Trethewey, and L. Willmitzer, "Simultaneous analysis of metabolites in potato tuber by gas chromatography-mass spectrometry," Plant Journal, vol. 23, no. 1, pp. 131-142, 2000.

[18] M. Stitt, "Rising $\mathrm{CO}_{2}$ levels and their potential significance for carbon flow in photosynthetic cells," Plant, Cell \& Environment, vol. 14, no. 8, pp. 741-762, 1991.

[19] R. Zrenner, K. Schüler, and U. Sonnewald, "Soluble acid invertase determines the hexose-to-sucrose ratio in coldstored potato tubers," Planta, vol. 198, no. 2, pp. 246-252, 1996. 


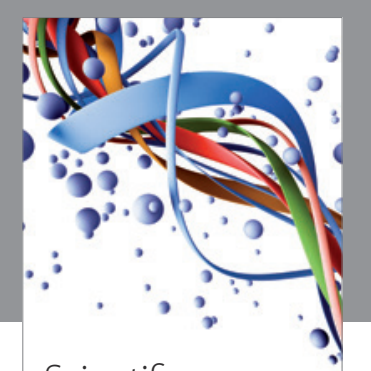

Scientifica
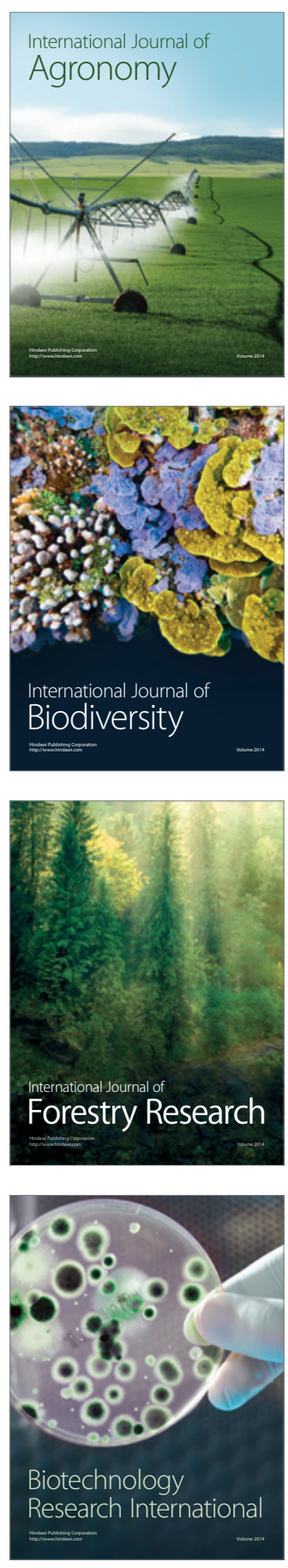
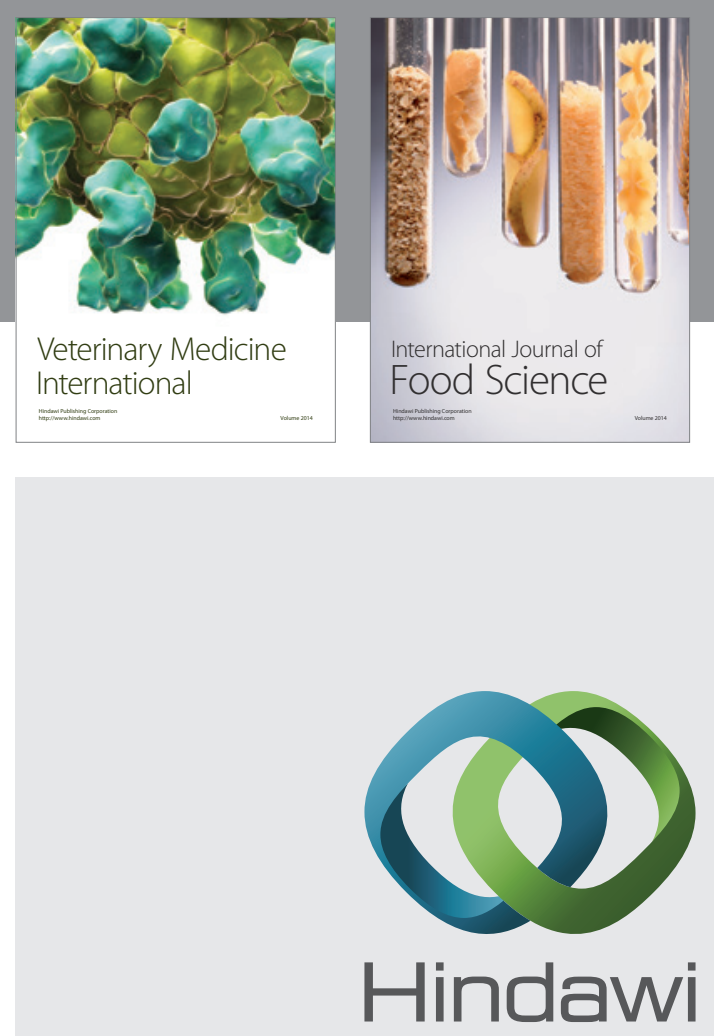

Submit your manuscripts at

http://www.hindawi.com
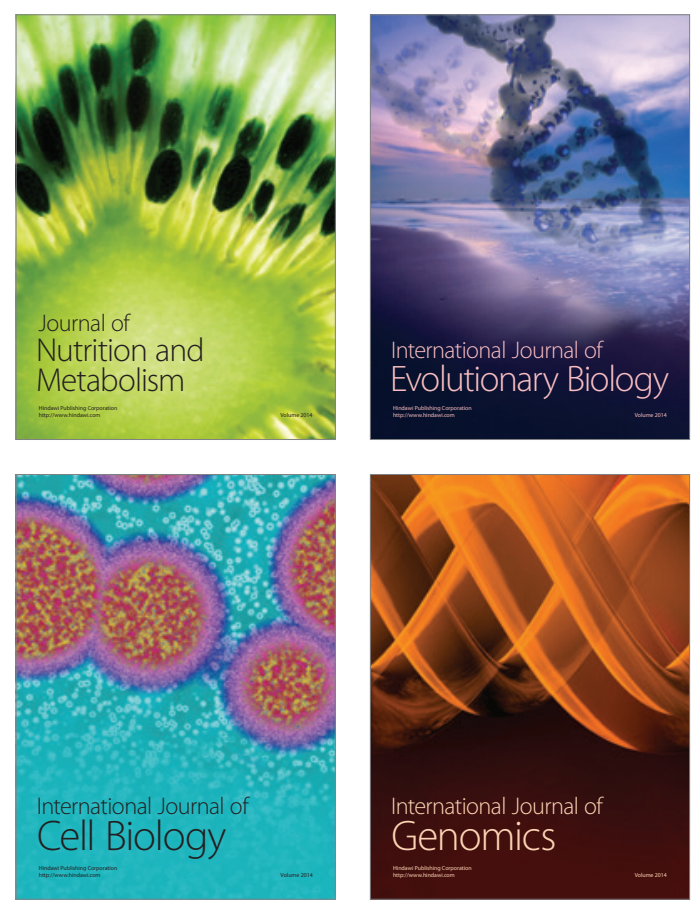
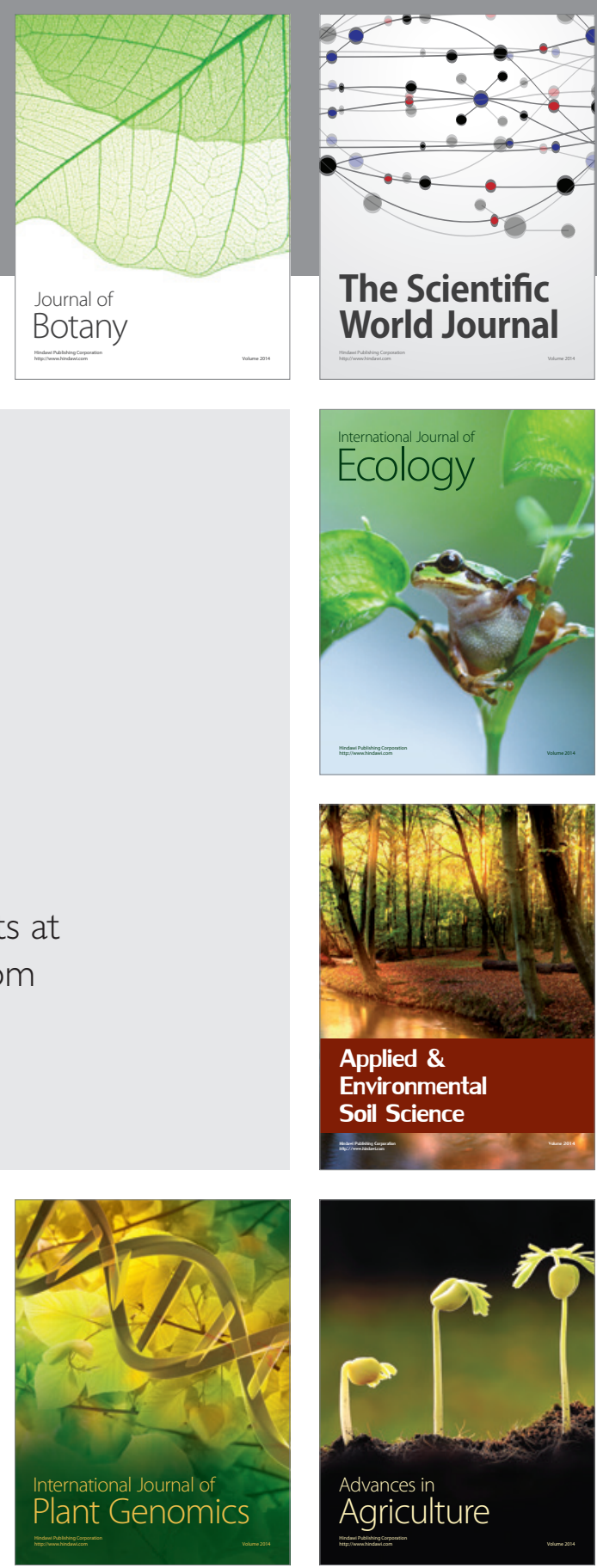

The Scientific World Journal
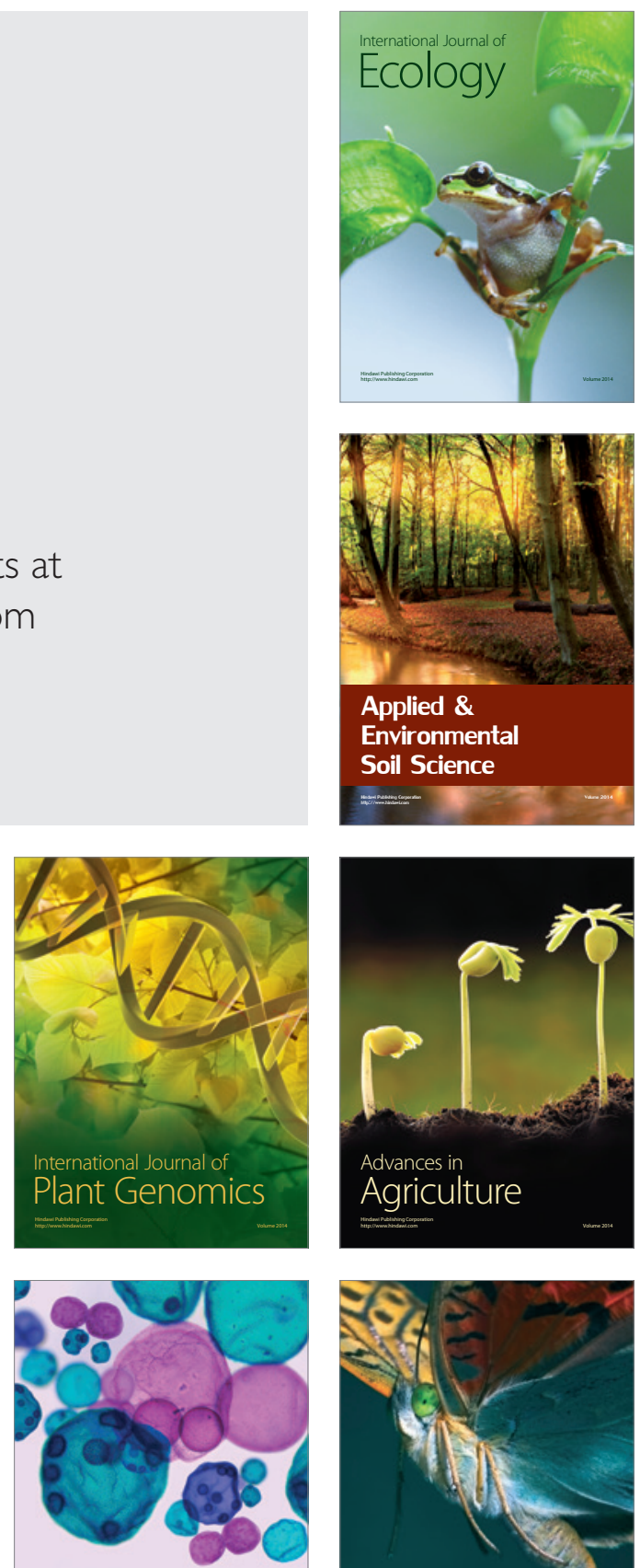

International Journal of Microbiology

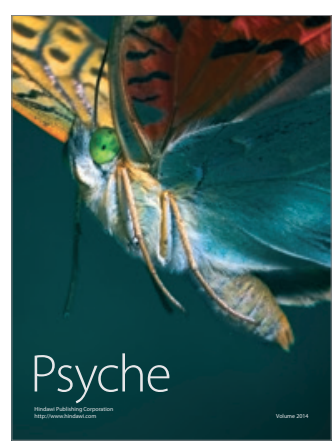

